\title{
Effect of lutein in development of experimental diabetic nephropathy in rats
}

\author{
Taruna Katyal, Gurpreet Singh, R. D. Budhiraja and Monika Sachdeva \\ Cardiovascular Pharmacology Divison, Indo Soviet Friendship College of Pharmacy, \\ Ghal Kalan, Moga-42001, Punjab, India.
}

Accepted 9 December, 2013

\begin{abstract}
The present study has been designed to investigate the effect of lutein in streptzotocin induced diabetic nephropathy in Wistar rats. Diabetic nephropathy (DN) was induced by administering single dose of streptozotocin in Wistar rats. DN was clinically assessed by the estimation of various biochemical parameters and histopathological studies of renal tissue. Diabetic nephropathy was assessed biochemically by blood urea nitrogen, serum creatinine, total urinary protein. Oxidative stress assessed by measuring the thiobarbituric acid reactive substances (TBARS) level and renal reduced glutathione levels. Treatment with high dose of lutein $(1.5 \mathrm{mg} / \mathrm{kg}$, p.o.) shows significant improvement in (blood urea nitrogen (BUN), serum creatinine, total urine protein, ratio of kidney wt/body wt, TBARS, reduced glutathione) renal parameters studied for DN. It may therefore be concluded that renoprotective effect of lutein is due to its antioxidant property. Lutein may prevent overproduction of reactive oxygen species (ROS) and increase the removal of preformed ROS. This may prove to be effective in preventing the development and progression of diabetic nephropathy.
\end{abstract}

Key words: Diabetic nephropathy, lutein, streptozotocin.

\section{INTRODUCTION}

Diabetic nephropathy (DN) is one of the complications of diabetes, and its morbidity and mortality is increasing worldwide. Diabetic nephropathy is characterized by thickening of glomerular basement membrane, glomerulosclerosis, glomerular hypertrophy, podocyte loss, expansion of mesangial cells and tubulointerstitial fibrosisn (Fowler, 2008). Diabetic nephropathy is associated with hyperactivity of sorbitol-aldose reductase pathway, hyperactivity of hexosamine biosynthetic pathway, activation of protein kinase, mitogen activated protein kinases and overexpression of growth factors and cytokines that is, transforming growth factor- $\beta$, vascular endothelial growth factor, platelet-derived growth factor and insulin-like growth factor (Arora et al., 2010).

Oxidative stress is an independent risk factor and major determinant of progression of nephropathy in patients with diabetes (Calabrese et al., 2007). Growing evidence suggested that oxidative stress may contribute to diabetic nephropathy and finally lead to end stage renal failure (Miyata et al., 2013). The elevated levels of reactive oxygen species has been found to activate protein kinase $\mathrm{C}$, transforming growth factor $\beta$, collagen IV, vascular endothelial growth factor which lead to deterioration of kidney (Soetikno et al., 2011). The reactive oxygen species (ROS) activates extracellular matrix accumulation in diabetic kidney (Lee and Song, 2009).

Recently, a carotenoid, lutein $\left[\left(3 R, 3^{\prime} R, 6^{\prime} R\right)\right.$ beta,epsilon-carotene-3,3'-diol] was found to be effective in reducing oxidative stress (Sindhu et al., 2012). Moreover, treatment with lutein reduces cell proliferation 
and apoptosis by decreasing expression of nuclear factor kappa B (NF-kappaB) in diabetic rats (Muriach et al., 2008). Lutein was shown to afford hepatoprotection by increasing the level of antioxidant enzymes, superoxide dismutase, catalase and glutathione levels in carbon tetra chloride treated rats (Sindhu et al., 2010). Therefore lutein can be considered as pure antioxidant. Extensive literature search revealed that the protective effect of lutein on other important complications of diabetes mellitus has not been explored yet. Therefore, the present study was designed to investigate the renoprotective effect of lutein in experimental DN in rats.

\section{MATERIALS AND METHODS}

Adult Wistar rats of either sex, weighing between 250 to $300 \mathrm{~g}$ were used in the study. The study was approved by the institutional animal committee.

Collection of blood sample was done from retro orbital sinus and blood glucose levels were estimated by glucose oxidase-peroxidise (GOD-POD) method (Lott et al., 1975).

\section{Assessment of diabetic nephropathy}

Blood urea nitrogen (BUN) was estimated by Berthelot method, total urinary protein was estimated by Pyragallol red method while serum creatinine was assessed by alkaline picrate method by using standard diagnostic kits (Bonsnes and 1945; Fawcett and Scott, 1960; Watanabe et al., 1986).

\section{Assessment of renal oxidative stress}

The development of oxidative stress in the kidney was assessed by estimating renal thiobarbituric acid reactive substances (TBARS) and reduced form glutathione content (GSH).

The kidney was dissected and washed with ice cold isotonic saline and weighed. The kidney was then minced, and a homogenate $(10 \% \mathrm{w} / \mathrm{v})$ was prepared in chilled $1.15 \% \mathrm{KCl}$. The homogenate was used for estimating TBARS, GSH.

The renal TBARS, an index of lipid peroxidation, was estimated according to the method described earlier (Ohkawa et al., 1979). The reaction mixture was prepared by mixing $0.2 \mathrm{ml}$ of tissue homogenate, $0.2 \mathrm{ml}$ of $8.1 \%$ sodium dodecyl sulphate (SDS), 1.5 $\mathrm{ml}$ of $20 \%$ acetic acid solution adjusted to $\mathrm{pH} 3.5$ with $\mathrm{NaOH}$ and $1.5 \mathrm{ml}$ of $0.8 \%$ aqueous solution of thiobarbituric acid (TBA). The reaction mixture was taken up to the level of $4.0 \mathrm{ml}$ with distilled water and then heated in water bath at $95^{\circ} \mathrm{C}$ for $60 \mathrm{~min}$. After cooling under tap water, $1.0 \mathrm{ml}$ of distilled water and $5.0 \mathrm{ml}$ of the mixture of $\mathrm{n}$-butanol and pyridine $(15: 1 \mathrm{v} / \mathrm{v})$ were added to the reaction mixture and shaken vigorously. After centrifugation at $4,000 \mathrm{rpm}$ for $10 \mathrm{~min}$, the organic layer was taken and its absorbance at $532 \mathrm{~nm}$ was measured. The standard curve using 1,1,3,3-tertramethoxyopropane was plotted to calculate the concentration of TBARS and the results were expressed as $\mathrm{nmol} / \mathrm{mg}$ of protein.

\section{Estimation of reduced glutathione}

The GSH level in the kidney was estimated by the method as described earlier (Ellman, 1959). Renal homogenate was mixed with $10 \% \mathrm{w} / \mathrm{v}$ trichloroacetic acid in ratio of $1: 1$ and centrifuged at $4^{\circ} \mathrm{C}$ for $10 \mathrm{~min}$ at $5,000 \mathrm{rpm}$. The supernatant obtained $(0.5 \mathrm{ml})$ was mixed with $2 \mathrm{ml}$ of $0.3 \mathrm{M}$ disodium hydrogen phosphate buffer $(\mathrm{pH}$ 8.4 ) and $0.4 \mathrm{ml}$ of distilled water. Then $0.25 \mathrm{ml}$ of $0.001 \mathrm{M}$ freshly prepared DTNB [5, 5'-dithiobis (2-nitrobenzoic acid) dissolved in 1\% $w / v$ sodium citrate] was added. The reaction mixture was incubated for $10 \mathrm{~min}$ and absorbance of yellow coloured complex was noted spectrophotometrically at $412 \mathrm{~nm}$. A standard curve was plotted using reduced form of glutathione and the results were expressed as $\mathrm{nmol} / \mathrm{mg}$ of protein.

\section{Histopathological studies}

The section of $3 \mu \mathrm{M}$ in thickness were made and stained with hematoxylin and eosin to assess the pathological changes of glomeruli using the light microscopy $(400 x)$.

\section{Experimental protocol}

Five groups were employed in the present study and each group comprised 6 rats: Group I (Normal control), rats were maintained on standard food and water regimen and no treatment was given. Group II (Diabetic control), rats were administered streptozotocin (50 mg/kg, i.p., once) dissolved in citrate buffer (pH 4.5). Group III (Lutein low dose treated diabetic group), the diabetic rats after 4 weeks of streptozotocin (STZ) administration were treated with lutein low dose $(0.5 \mathrm{mg} / \mathrm{kg}$, p.o) for 4 weeks. Group IV (Lutein medium dose treated diabetic group), the diabetic rats after 4 weeks of STZ administration were treated with lutein medium dose (1 mg/kg, p.o) for 4 weeks, Group V (Lutein high dose treated diabetic group), the diabetic rats after 4 weeks of STZ administration were treated with lutein high dose $(1.5 \mathrm{mg} / \mathrm{kg}, \mathrm{p} .0)$ for 4 weeks.

\section{Statistical analysis}

All values were expressed as mean \pm standard deviation (SD). Data obtained from different groups were statistically analyzed using twoway analysis of variance (ANOVA) followed by Tukey's multiple comparison tests. The $P<0.05$ was considered to be statistically significant.

\section{Drugs and chemicals}

Lutein was obtained from Omni Active Health Technologies Private Limited, Mumbai as an Ex-gratia. STZ was obtained from Sigma Aldrich Ltd, St. Louis, USA. All other chemicals used in present study were of analytical grade.

\section{RESULTS}

\section{Effect of lutein on serum glucose level in diabetic rats}

After administration of STZ, the rats that showed blood glucose greater than $250 \mathrm{mg} / \mathrm{dl}$ were selected and grouped as diabetic rats. However, treatment with low and medium dose of lutein did not produce any significant anti hyperglycaemic effect in STZ treated rats. Moreover, high dose of lutein significantly decreased serum glucose levels in diabetic rats (Figure 1). 


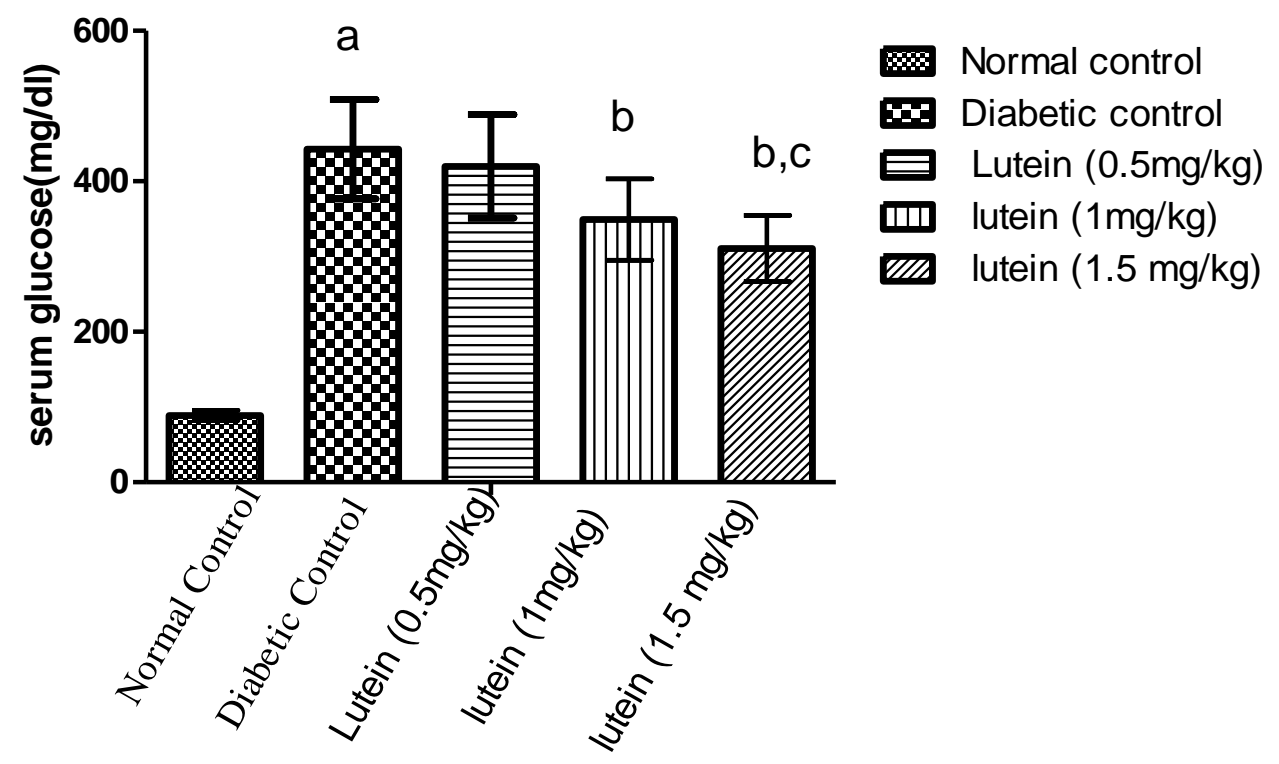

Figure 1. Effect of lutein treatment in different doses on Serum glucose level in $n / p$ subjected diabetic rats. All values are expressed as Mean \pm S.D. $a=p<0.05$ Vs normal control, $b=p<0.05$ Vs diabetic control, $\mathrm{C}=p<0.05 \mathrm{Vs}$ lutein $(0.5 \mathrm{mg} / \mathrm{kg})$.

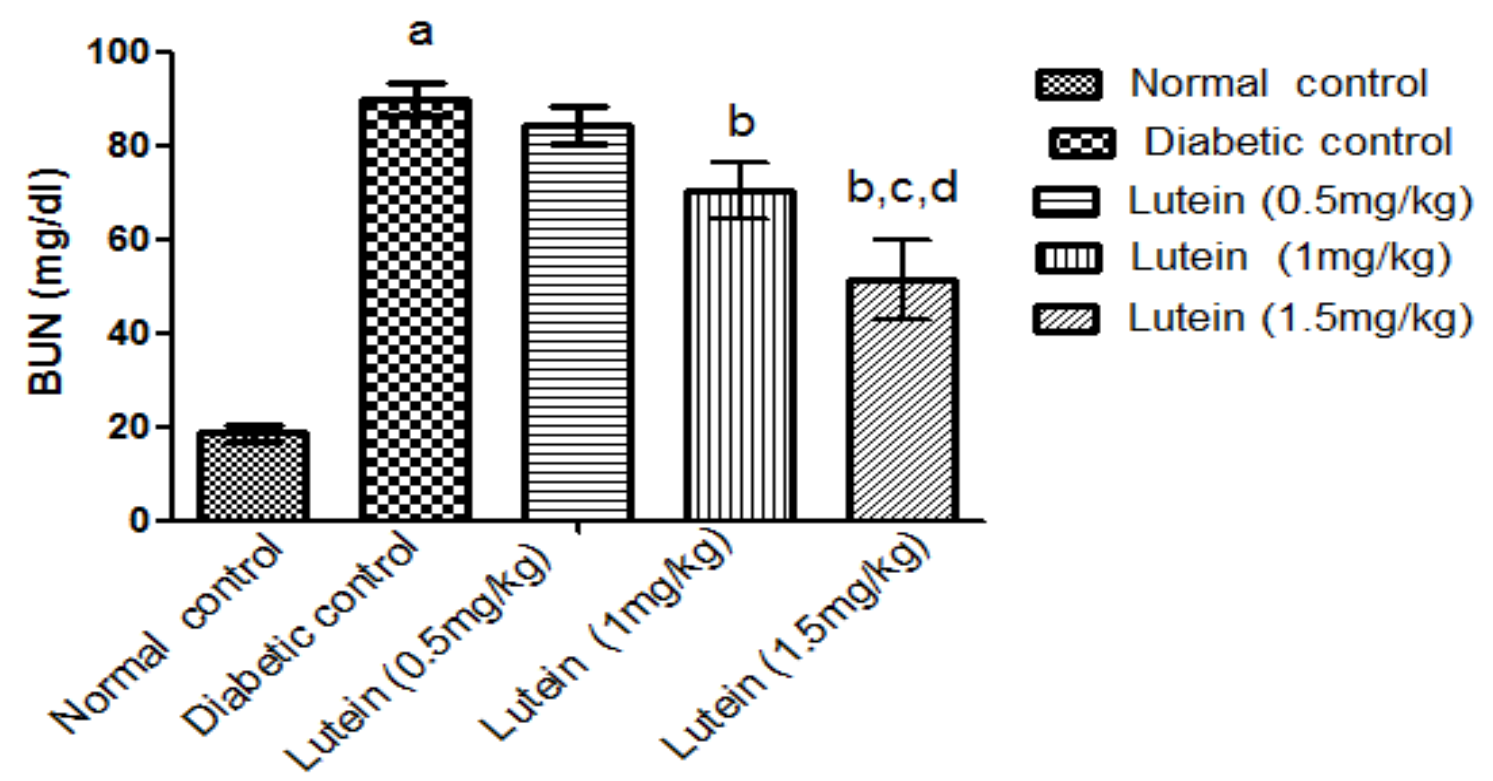

Figure 2. Effect of lutein treatment in different doses on BUN level in $\mathrm{n} / \mathrm{p}$ subjected diabetic rats. All values are expressed as Mean \pm S.D. $a=p<0.05$ vs normal control, $\mathrm{b}=p<0.05$ vs diabetic control, $\mathrm{c}=p<0.05$ vs lutein $(0.5 \mathrm{mg} / \mathrm{kg}), \mathrm{d}=p<0.05$ vs lutein $(1.0 \mathrm{mg} / \mathrm{kg})$.

\section{Effects of lutein on blood urea nitrogen, serum creatinine and total urine protein}

The marked increase in BUN, serum creatinine and total urinary protein were noted in diabetic rats as compared to normal rats. However, treatment with low and medium dose of lutein reduced the level of BUN, serum cretinine and total urinary protein in diabetic rats. Moreover, 4 weeks treatment of high dose lutein was only found to be statistically significant (Figure 2 and Table 1). 


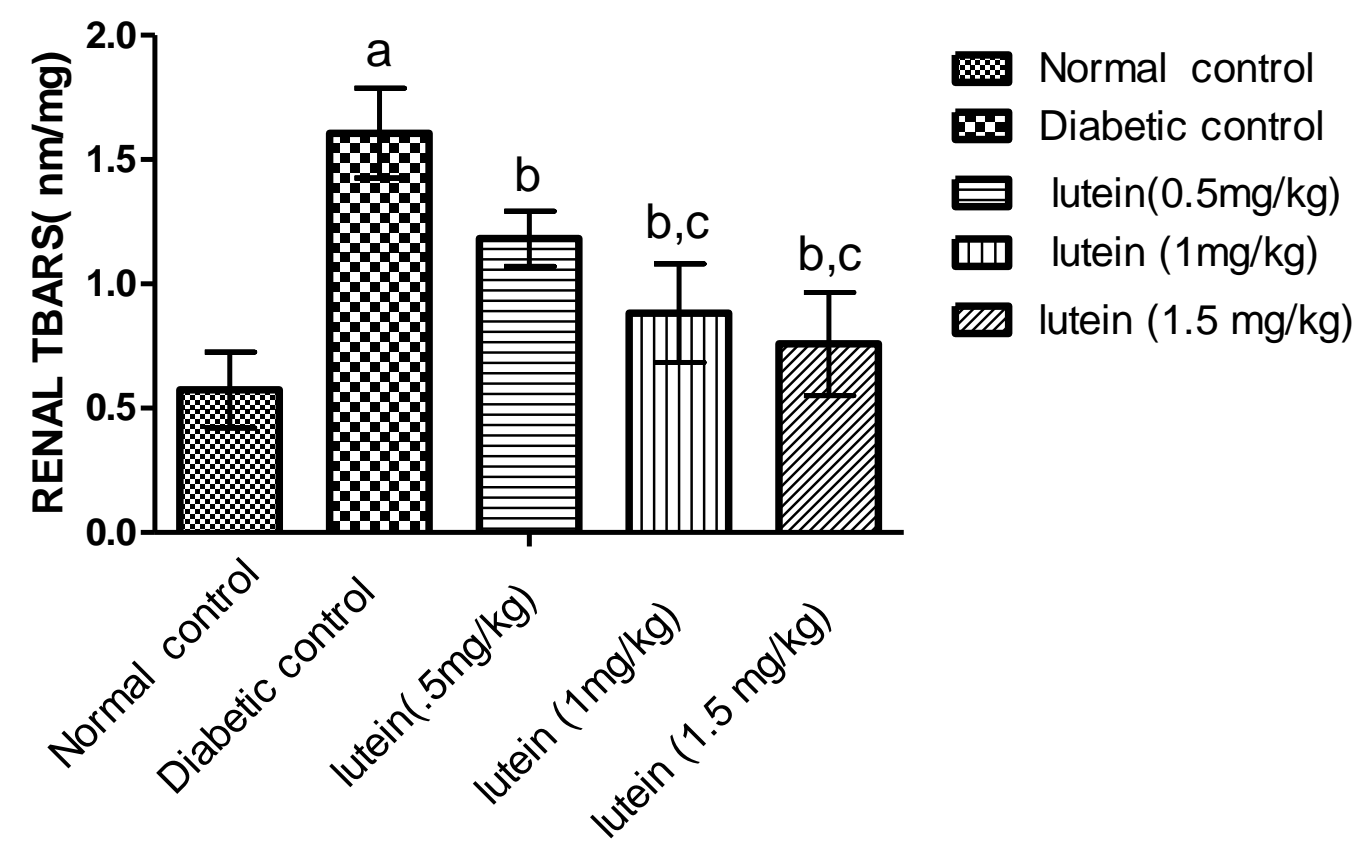

Figure 3. Effect of lutein treatment in different doses on renal TBARS level on $n / p$ subjected diabetic rats. All values are expressed as Mean \pm S.D. $a=p<0.05$ vs normal control, $\mathrm{b}=p<0.05$ vs diabetic control, $\mathrm{c}=$ $p<0.05$ vs lutein $(0.5 \mathrm{mg} / \mathrm{kg})$.

with renal failure. In the present study, diabetes mellitus was induced by single administration of streptozotocin (50 $\mathrm{mg} / \mathrm{kg}$, i.p) (Vaishya et al., 2008) which damages the DNA of pancreatic- $\beta$ cells by activating protein kinase-C, poly(ADP-ribose) polymerase (PARP) and $\mathrm{NAD}(\mathrm{P}) \mathrm{H}$ oxidase to generate $R O$. The increased level of blood

\section{Effects of lutein on kidney weight/body weight}

An increase in kidney weight/body weight (\%) was observed in diabetic rats as compared to normal rats. The treatment with low and medium dose of lutein slightly decreased the kidney weight/body weight ratio when compared with diabetic rats. This reduction was found to be significant only in case of high dose of lutein (Table 1).

\section{Effects of lutein on renal oxidative stress}

The marked increase in the level of renal TBARS and decrease in the level of reduced form of glutathione were noted in diabetic rats as compared to normal rats. The treatment of low and medium dose of lutein decreased the renal TBARS and increased the reduced renal glutathione. However, high dose of lutein significantly reduced the renal TBARS and increased the reduced renal glutathione level (Figures 3 and 4).

\section{Histopathological studies}

The diabetic rats were found to develop pathological changes in the glomeruli such as glomerular capillary size reduction and extracellular mesangial expansion as compared to normal rats. The administration of lutein (1.5 $\mathrm{mg} / \mathrm{kg}$, p.o) markedly reduced the pathological changes in glomeruli by improving the glomerular capillary size and reducing the mesangial expansion (Figure 5).

\section{DISCUSSION}

Diabetic nephropathy is an injurious disorder associated glucose was noted as a marker of hyperglycemia. Hyperglycemia induced-oxidative stress was caused by free radical generation and decrease antioxidant defense system (Balakumar et al., 2009). The increase in renal TBARS and decrease in GSH levels are considered to be an index of development of oxidative stress (Balakumar et al., 2009). The increase in creatinine (serum), BUN and total urine protein were noted as a marker of renal dysfunction (Bader et al., 1980; Perrone et al., 1992; Vaishya et al., 2008).

In the present study, the serum creatinine, blood urea nitrogen and proteinuria were noted to be significantly increased in STZ-induced diabetic rats as compared to normal rats. The increased ratio of kidney weight/body weight may contribute to renal hypertrophy which leads to 


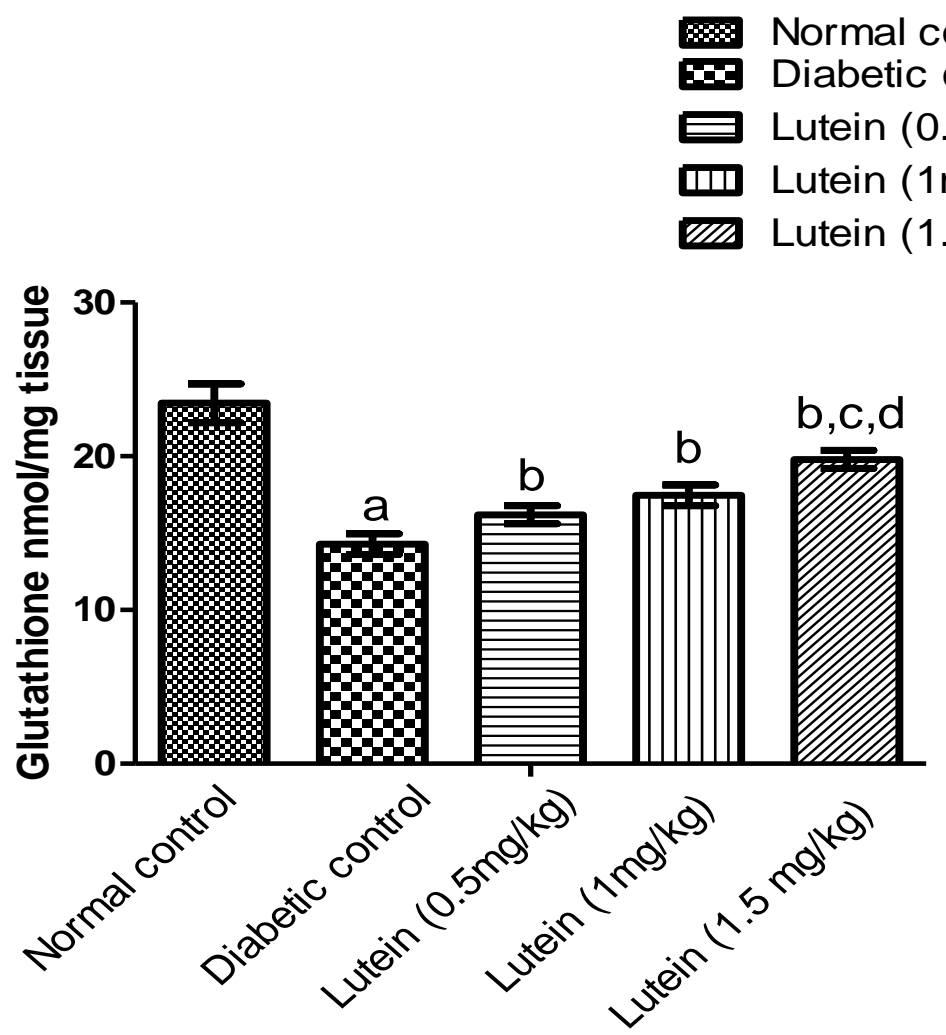

Figure 4. Effect of lutein treatment in different doses on renal glutathione level $n / p$ subjected diabetic rats. All values are expressed as Mean \pm S.D. $a=p<0.05$ vs normal control, $\mathrm{b}=p<0.05$ Vs diabetic control, $\mathrm{c}=p<0.05$ vs lutein $(0.5 \mathrm{mg} / \mathrm{kg}), \mathrm{d}=p<0.05$ vs lutein $(1.0 \mathrm{mg} / \mathrm{kg})$.

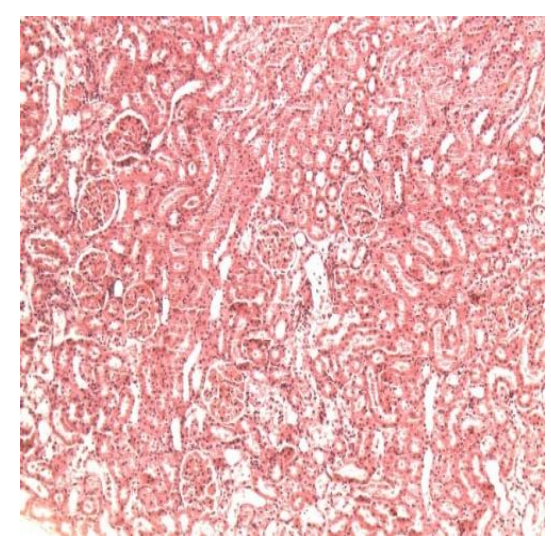

(A)

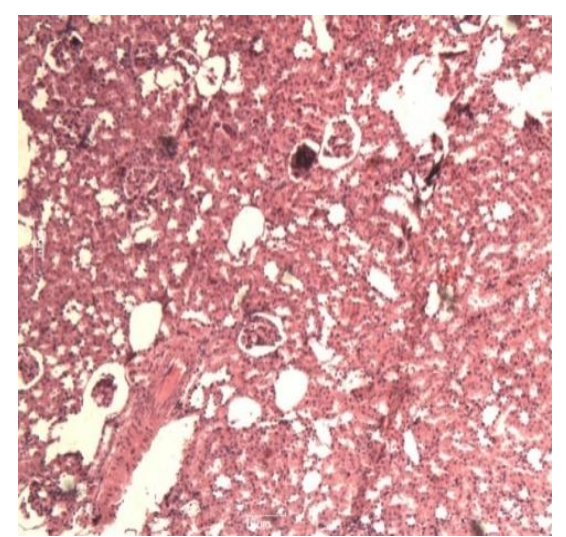

(B)

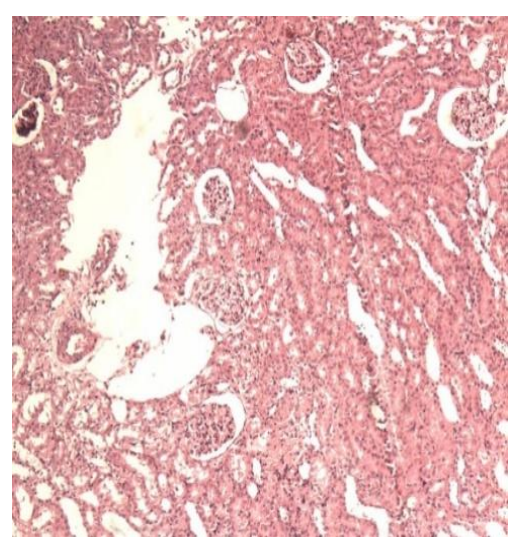

(C)

Figure 5. Histopathological slides: Haematoxylin Eosin staining of kidney of the rats at (40X) in various groups (A) Normal control $\quad$ B) STZ Treated C) STZ Treated + Lutein.

diabetic nephropathy progression (Fujisawa et al., 2004). These words are supported by our study that there is significant increase in the ratio of kidney weight/body weight in diabetic rats. Persistent hyperglycemia in diabetes mellitus produces oxidative stress due to increased generation of ROS as well as decreased expression and 
Table 1. Effect of lutein treatment in different doses on serum creatinine, total urine protein, kidney wt/body wt in diabetic rats.

\begin{tabular}{cccc}
\hline Groups & Serum Creatinine (mg/dl) & Total urine protein (mg/dl) & Kidney wt/body wt \\
\hline Normal Control & $0.81 \pm \mathrm{s} 0.39$ & $5.30 \pm 0.795$ & $0.53 \pm 0.04$ \\
Diabetic Control & $1.68 \pm 0.14^{\mathrm{a}}$ & $105.94 \pm 7.90^{\mathrm{a}}$ & $0.70 \pm 0.05^{\mathrm{a}}$ \\
Lutein (0.5mg/kg, p.o.) & $1.53 \pm 0.12$ & $83.23 \pm 5.57^{\mathrm{b}}$ & $0.6 \pm 0.6$ \\
Lutein (1.0mg/kg,p.o.) & $1.19 \pm 0.16^{\mathrm{b}}$ & $66.47 \pm 4.32^{\mathrm{b}, \mathrm{c}}$ & $0.47 \pm 0.039^{\mathrm{b}}$ \\
Lutein (1.5mg/kg,p.o.) & $1.021 \pm 0.168^{\mathrm{b}, \mathrm{c}}$ & $55.78 \pm 5.39^{\mathrm{b}, \mathrm{c}, \mathrm{d}}$ & $0.35 \pm 0.043^{\mathrm{b}, \mathrm{d}}$ \\
\hline
\end{tabular}

All values are expressed as Mean \pm S.D. $\mathrm{a}=p<0.05$ vs normal control, $\mathrm{b}=p<0.05$ vs diabetic control, $\mathrm{c}=p<0.05$ vs lutein $(0.5 \mathrm{mg} / \mathrm{kg}), \mathrm{d}=p<0.05 \mathrm{Vs}$ lutein $(1.0 \mathrm{mg} / \mathrm{kg})$.

activity of anti-oxidant enzyme. The increase in renal TBARS and decrease in GSH levels are considered to be an index of development of oxidative stress (Balakumar et al., 2009). In this study increase renal TBARS and decrease in renal glutathione were observed in diabetic rats. Thus it may suggest that diabetes-induced development of oxidative stress may develop nephropathy by damaging renal architecture.

However, treatment with the anti-oxidant drugs that is, lutein $(1.5 \mathrm{mg} / \mathrm{kg}$, p.o.), partially prevented the development of nephropathy in diabetic rats by effectively inhibit high-glucose and $\mathrm{H}_{2} \mathrm{O}_{2}$ induced transforming growth factor- $\beta 1$ and fibronectin upregulation, thus providing evidence that ROS play an important role in high glucoseinduced renal injury.

The flavonoid lutein has been shown to possess direct antioxidant activity, therefore we hypothesize that it may be useful in treatment of many chronic disease associated with oxidative stress, such as diabetic nephropathy via its antioxidant properties. The protection against development of diabetic nephropathy by lutelin treatment involved changes in superoxide dismutase (SOD) activity, the malondialdehyde (MDA) content and expression of heme Oxygenase-1 (HO-1) protein (Jiro et al., 2009).

The decrease in reduced glutathione (GSH) level has been observed during reduced intra-cellular antioxidant defence system. Hence, these parametes have been used in the present study to assess the degree of oxidative stress. In the present study, the increase in serum TBARS, which is the index of lipid peroxidation was noted in diabetic rats. Moreover, reduced glutathione level was noted to be decreased in diabetic rats. These results suggest the development of oxidative stress in diabetic rats. In the present study, the administration of lutein significantly attenuated the STZ-induced increase in blood glucose level. The treatment with lutein significantly attenuated the diabetic-induced increase in TBARS level and decrease in reduced glutathione level. Thus, it may be suggested that the reduction in blood glucose level with lutein may be to their antioxidant properties and reduction in oxidative stress in $\beta$-cells of islets of langerhans. Moreover, the results obtained in the present study is further supported by the recent report in which lutein, an antioxidant bioflavanoids has been shown to scanvenge free redicals, inhibit lipid peroxidation and protect $\beta$-cells of langerhans, resulting in increased secretion and decreased blood glucose level (Narayanan et al., 1993).

The increase in blood urea nitrogen and serum creatinine is reported to be an index of altered glomerulor filtration rate (GFR) in diabetic nephropathy. Further, the decrease in creatinine clearance occurs in diabetic rats with nephropathy due to progressive renal damage and reduction in GFR. It has been reported that decreased GFR has been associated with the formation of reactive oxygen species (ROS) (Chen et al., 2006).). In the present study, lutein has attenuated diabetic-induced increase in blood urea nitrogen, serum creatinine in diabetic rats, which may be due to their reduction in the formation of ROS. The activation of polyol, protein kinase $C$ (PKC), AGE and hexoamine have been shown to play a key role in the pathogenesis of diabetic nephropathy (Fowler, 2008). It has been reported that diabetic-induced oxidative stress involves activation of various signaling pathways such as polyol, PKC, AGE and hexoamine. Thus the ameliorative effect of lutein in diabetes-induced nephropathy may be due to their antioxidant property and consequent inhibition of polyol, PKC, AGE and hexoamine pathways.

\section{Conclusion}

The findings of present study strongly suggest that oxidative stress play a key role in the pathogenesis of diabetic nephropathy. The treatment with lutein shows renoprotective effect due to its antioxidant property.

\section{REFERENCES}

Arora MK, Reddy K, Balakumar P (2010). The low dose combination of fenofibrate and rosiglitazone halts the progression of diabetesinduced experimental nephropathy. Eur. J. Pharmacol. 636:137-144.

Bader R, Bader H, Grund KE, Mackensen HS, Christ H, Bohle A (1980). Structure and function of kidney in diabetic glomerulosclerosis correlations between morphological and functional parameters. Pathol. Res. Pract. 2-4:204-216.

Balakumar P, Chakkarwar VA, Singh M (2009). Ameliorative effect of combination of benfotiamine and fenofibrate in diabetesinduced vascular endothelial dysfunction and nephropathy in the rat. Mol. Cell 
Biochem. 1-2:149-162 .

Bonsnes RW, Taussky HH (1945). On the colorimetric determination of creatinine by the Jaffe reaction. J. Biol. Chem. 3:581-591.

Calabrese V, Mancuso C, Sapienza M, Puleo E, Calafato S, Cornelius C, Finocchiaro M, Mangiameli A, Di Mauro M, Stella AM, Castellino P (2007). Oxidative stress and cellular stress response in diabetic nephropathy. Cell Stress Chaperones 12:299-306.

Chen LL, Zhang JY, Wang BP (2006). Renoprotective effects of fenofibrate in diabetic rats are achieved by suppressing kidney plasminogen activator inhibitor-1. Vasc. Pharmacol. 44:309-315.

Ellman GL (1959). Tissue Sulfhydryl groups. Arch. Biochem. Biophys. 1:70-77.

Fawcett JK, Scott E (1960). A rapid and precise method for the determination of urea. J. Clin. Pathol. 13:156-159.

Fowler MJ (2008). Microvascular and macrovascular complications of diabetes. Clin. Diabetes 26:77-82.

Fujisawa G, Okada K, Muto S, Futija N, Itabashi N, Kusano E, Ishibashi $S$ (2004). Spironolactone prevents early renal injury in streptozotocininduced diabetic rats. Kidney Int. 66:1493-1502.

Lee HS, Song CY (2009). Oxidized low-density lipoprotein and oxidative stress in the development of glomerulosclerosis. Am. J. Nephrol. 29:62-70.

Jiro T, Kazuhiko T, Hirofumi I, Hideko N, Hidek YKF, kawa M, TaniguchiMitsuo L (2009). Spironolactone inhibitshyperglycemiainduced podocyte injury by attenuating ROS production. J. Endocrine 83:765-980.

Lott JA, Turner K (1975). Evaluation of Trinder's glucose oxidase method for measuring glucose in serum and urine. Clin. Chem. $21: 1754-1760$.

Miyata T, Suzuki N, van Ypersele de Strihou C (2013). Diabetic nephropathy: are there new and potentially promising therapies targeting oxygen biology? Kidney Int. doi: 10.1038/ki.2013.74.
Muriach M, Bosch-Morell F, Arnal E, Alexander G, Blomhoff R, Romero FJ (2008). Lutein prevents the effect of high glucose levels on immune system cells in vivo and in vitro. J. Physiol. Biochem. 64:149157.

Narayanan S (1993). Aldose reductase and its inhibition in the control of diabetic complications. Ann. Clin. Lab. Sci. 23:148-158.

Ohkawa H, Ohishi N, Yagi K. (1979). Assay for lipid peroxides in animal tissue by thiobarbituric acid reaction. Anal. Biochem. 2:351-358.

Perrone RD, Madias NE, Levey AS (1992). Serum creatinine as an index of renal function: New insight into old concepts. Clin. Chem. 38:1933-1953.

Sindhu ER, Firdous AP, Preethi KC, Kuttan R (2010). Carotenoid lutein protects rats from paracetamol-, carbon tetrachloride- and ethanolinduced hepatic damage. J. Pharm. Pharmacol. 62:1054-1060.

Sindhu ER, Kuttan R (2012). Carotenoid lutein protects rats from gastric ulcer induced by ethanol. J. Basic Clin. Physiol. Pharmacol. 23:33-37.

Soetikno V, Watanabe K, Sari FR, Harima M, Thandavarayan RA, Veeraveedu PT, Arozal W, Sukumaran V, Lakshmanan AP, Arumugam S, Suzuki K (2011). Curcumin attenuates diabetic nephropathy by inhibiting PKC- $\alpha$ and PKC- $\beta 1$ activity in streptozotocin-induced type I diabetic rats. Mol. Nutr. Food Res. 55:1655-1665.

Vaishya R, Singh J, Lal H (2008). Effect of irbesartan on streptozotocininduced diabetic nephropathy: an interventionary study. Indian J. Clin. Biochem. 2:195-197.

Watanabe N, Kamei S, Ohkubo A, Yamanaka M, Ohsawa S, Makino K, Tokuda K (1986). Urinary protein as measured with a pyragallol redmolybdate complex manually and in a Hitachi 726 automated analyzer. Clin. Chem. 32:1551-1554. 